\title{
Распространения импульсного давления при электрогидравлическом бурении
}

\author{
(c) Б.А. Ахмадиев, ${ }^{1,2}$ А. Татыбеков, ${ }^{2}$ Н.Н. Шуюшбаева, ${ }^{3}$ Н.К. Танашева ${ }^{4}$ \\ ${ }^{1}$ Карагандинский государственный университет им. Е.А. Букетова, \\ 100028 Караганда, Казахстан \\ ${ }^{2}$ Кыргызкий государственный технический университет им. И. Раззакова, \\ 720064 Бишкек, Кыргызстан \\ ${ }^{3}$ Кокшетауский государственный университет им. Ш. Уалиханова, \\ 020001 Кокшетау, Казахстан \\ ${ }^{4}$ Институт прикладной математики, \\ 100028 Караганда, Казахстан \\ e-mail: nazgulya_tans@mail.ru
}

(Поступило в Редакцию 14 мая 2018 г. В окончательной редакции 5 октября 2018 г.)

Рассмотрено распространение импульсного давления, которое создается электрическими разрядами в неоднородной жидкости при бурении скважин. Приведены численные расчеты динамики давления на основе термодинамического анализа нелинейного процесса электрогидравлического эффекта в гетерогенной среде. По результатам исследования получены зависимости относительного давления и координаты фронта ударной волны от времени.

DOI: $10.21883 /$ JTF.2019.04.47302.189-18

\section{Введение}

В настоящее время во многих развитых странах открытие и использование нетрадиционных источников энергии оказывает значительное влияние на развитие экономики страны. Именно поэтому современное развитие энергетического сектора Республики Казахстан характеризуется реорганизацией топливноэнергетического комплекса. Это связано с ростом цен на топливо на мировом рынке и проблемами окружающей среды. Одним из способов решения этих проблем является внедрение новых энергосберегающих технологий, в которых используются нетрадиционные возобновляемые источники энергии.

Сегодня во многих странах различные способы производства энергии рассматриваются в соответствии с текущими тенденциями. Технология теплового насоса является одним из наиболее эффективных методов. Экологическая эффективность этой технологии заключается в том, что она помогает предотвратить выбросы парниковых газов. Поэтому одним из основных и актуальных вопросов является развитие технологии тепловых насосов, а не замена старых котлов при использовании в системе газового и жидкого топлива.

Для использования низкотемпературной тепловой генерации необходимо подготовить скважины для установки теплообменников теплового насоса. Горизонтальные и вертикальные скважины могут быть реализованы с использованием различных методов бурения. Электрогидроимпульсный метод разрушения горных пород отличается от механического метода низким потреблением энергии и высокой эффективностью [1-4].
Целью настоящей работы является расчет импульсного давления в гетерогенных средах.

В настоящей работе рассматривается моделирование гидродинамики электрогидравлического эффекта, где предполагается изотропность всех процессов, а именно волны возмущения, кроме того, предполагается, что и все другие параметры меняются одинаково по всем направлениям. В проведенных нами экспериментах была обнаружена возможность концентрирования мощности ударной волны при помощи твердого отражателя, которая представляет собой внутреннюю часть электрогидравлического бура, изготовленого в виде параболоида.

\section{Методика численного расчета}

Экспериментальные данные, полученные измерением импульсного давления в гетерогенных средах при различных условиях [5-8], показали необходимость исследования закономерностей давления отраженных волн от твердой границы при максимальной амплитуде в пузырьковой жидкости.

Для проведения численного расчета использовались дифференциальные уравнения, которые позволяют определить при заданных начальных условиях, изменение давления $P(t)$ взрыва по времени и размеры разряда $x(t)$.

Проведенные нами численные расчеты динамики давления на основе термодинамического анализа нелинейного процесса электрогидравлического эффекта в гетерогенной среде учитывают влияние степени дисперсности среды и изменения геометрии канала на распространение ударной волны посредством введения уточняющих коэффициентов в уравнение теплового баланса. 


\section{Результаты численного расчета}

Мощность, выделяемая при электрогидравлическом эффекте, запишем в следующем виде:

$$
N(t)=\frac{d Q(t)}{d t}=\frac{1}{k(\varphi)-1}\left(V P^{\prime}+k(\varphi) P V^{\prime}\right),
$$

где $N(t)$ - мощность, $Q(t)$ - энергия, выделяемая при электрическом разряде, $P$ - давление рабочей среды, $V$ - объем канала разряда, $k-$ показатель политропы. Величины со штрихами обозначают дифференциалы по времени. Давление $P$ на первом шаге равно максимальному значению давления на фронте ударной волны, которое определяется из условия Гюгония:

$$
P=\frac{2 \rho_{0}}{k+1} u^{2}=C_{1} u^{2}
$$

где $C=\frac{2 \rho_{0}}{k+1}-$ коэффициент, учитывающий нелинейные свойства гетерогенной среды с плотностью $\rho_{0}$ в невозмущенном состоянии.

Скорость распространения ударной волны $(u)$ находится по следующей формуле (3):

$$
u=\frac{d x(t)}{d t}
$$

где $x$ - пространственная координата.

Объем пространства, в котором происходит распространение ударной волны, равен объему некоторого параболоида. Если направить ось параболоида по направлению движения ударной волны, тогда радиус основания совпадет с радиусом рабочего канала (рис. 1). При этом предполагается, что высоковольтный кабель-электрод, который является источником мощного импульсного давления, расположен между фокусом и двойным фокусом параболоида. Тогда высота параболоида направлена по оси $x$, а радиус основания $r$ определяется значением перпендикулярной оси координаты.

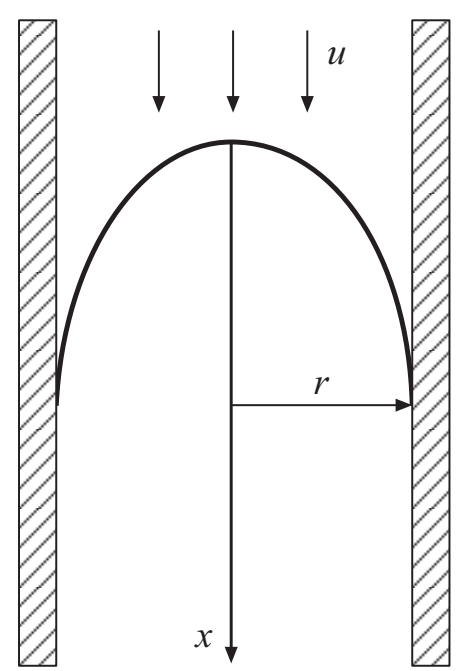

Рис. 1. Схема расчета объема разрядного пространства.

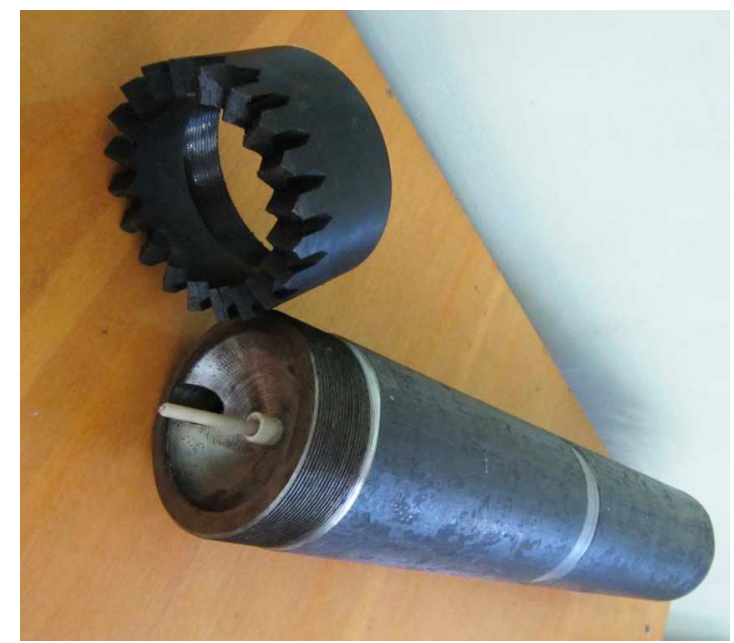

Рис. 2. Электрогидравлический бур.

Рабочий объем окружающего канал разряда $(V)$, как и объем параболоида, находится по формуле (4)

$$
V=C_{2} x^{2}
$$

где $C_{2}=\frac{2}{3} \pi r \operatorname{tg} \theta-$ коэффициент, зависящий от геометрических параметров канала распространения ударной волны, $r$ - радиус рабочей части трубы, $\theta-$ угол, равный отношению радиуса к высоте параболоида.

При наличии ограничивающих стенок рабочего участка в виде параболоида, коэффицицент $C_{2}$ зависит от расположения центрального кабеля-электрода, который учитывает влияние ограничивающихся отражателей. На рис. 2 показан электрогидравлический бур.

Используя выражения (2)-(4), преобразуем уравнение (1) и получим следующую систему для расчета эволюции давления и скорости распространения ударной волны:

$$
\left\{\begin{array}{l}
P^{\prime}=\frac{k-1}{C_{2}} \frac{N(t)}{x^{2}}-2 k \sqrt{\frac{P^{3}}{C_{1}}} \frac{1}{x(t)} \\
x^{\prime}= \pm \sqrt{\frac{P}{C_{1}}}
\end{array}\right.
$$

С точки зрения гидродинамики, ударная волна, распространяющаяся вдоль оси параболоидного отражателя, где давление на фронте используется для разрушения твердых камней, представляет собой затопленную турбулентную струю, как известно, не имеющую до сих пор теоретического описания. В работах [9-11] приведены результаты современных исследований динамики турбулентных процессов.

Сущность данного подхода основана на рассмотрении явления перемежаемости в турбулентном перемешивании, заключающегося в чередовании по времени в фиксированной точке турбулентной и невозмущенной жидкости. Вся струя рассматривается как смесь двух 


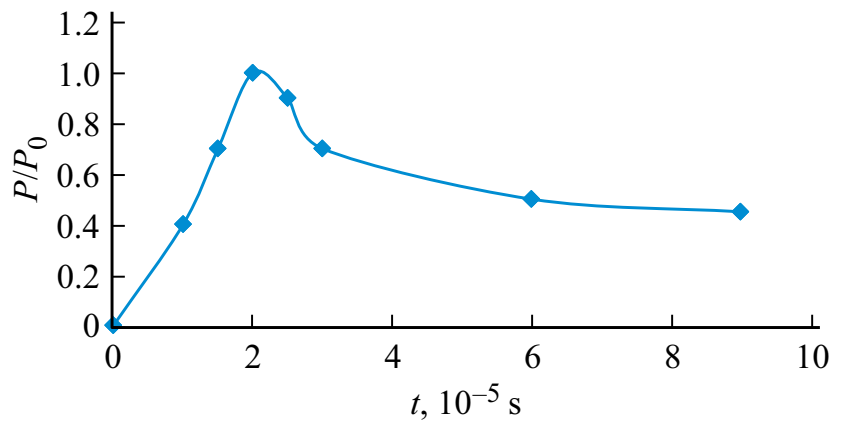

Рис. 3. Давление в разрядном канале в зависимости от времени.

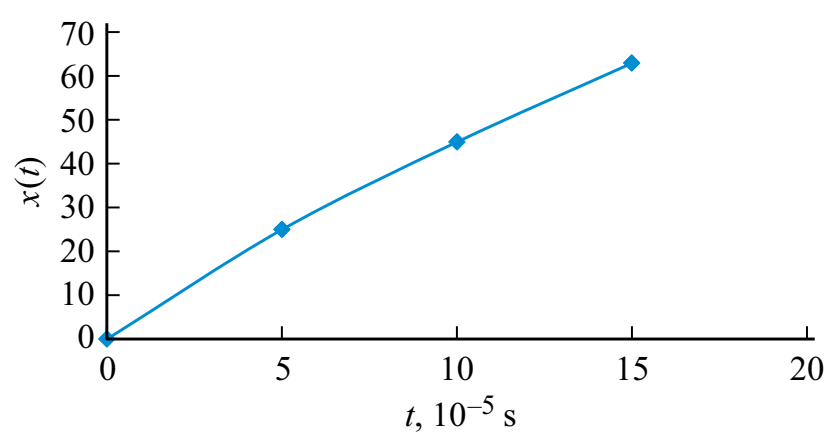

Рис. 4. Зависимость координаты ударной волны в разрядном канале от времени.

жидкостей: турбулентной и невозмушенной. Вероятность появления турбулентной жидкости в заданной точке характеризуется коэффициентом перемежаемости, который определяется через относительное значение масштаба турбулентности или пульсации скорости (явление чередования ламинарной и турбулентной форм движения называется перемежаемостью).

Для численного расчета необходимо задать значение функции и ее производные в одной точке, при котором начальный момент времени равен нулю $(t=0)$. Данные числовые результаты получены с помощью программы Паскаль, а также построены графики зависимости относительного давления и координаты ударной волны от времени в пакете MathCad, которые показаны на рис. 3 и 4.

\section{Заключение}

На основе полученных расчетных и экспериментальных данных получены следующие результаты:

- проведены численные расчеты динамики давления на основе термодинамического анализа нелинейного процесса электрогидравлического эффекта в гетерогенной среде;

- выявлено увеличение амплитуды импульсного давления в определенных местах центрального кабеляэлектрода в параболоидном отражателе бура. Этот факт свидетельствует о случае предельно развитой и самоорганизованной турбулентности, т.е. комбинации вихрей, образуемых при отражении от твердых отражателей случай своего рода некоторого резонанса наложения отраженных ударных волн.

- при электровзрыве энергия ударной волны распространяется во все стороны изотропно, и с помощью параболоидного отражателя она может концентрироваться в одном преимущественном направлении. Наибольшая эффективность была зафиксирована при расположении кабеля-электрода между фокусом и двойным фокусом параболоидного отражателя.

\section{Список литературы}

[1] Малюшевский П.П. Основы разрядно-импульсной технологии. Киев: Наук. думка, 1983. С. 272

[2] Бельков Е.П., Бочаров Ю.Н., Шнеерсон Г.А., Янчус Э.И. Генератор импульсных токов. Учебн. пособие. СПбГТУ, $1998.99 \mathrm{c}$.

[3] Воробьев А.А. Разрушение горных пород электрическими импульсными разрядами. Томск: Изд-во ТГУ, 1961. $150 \mathrm{c.}$

[4] Сакипова C.E. К расчету импульсного давления при электроразрядном воздействии в неоднородной жидкости. // Вестник ТГУ. 2009. № 1 (5). С. 74-81.

[5] Прибатурин Н.А., Стасенко Д.П. // ПМТФ. 2000. Т. 41. № 2. C. 64-69.

[6] Донщов В.E. // Сб. Акустика неоднородных сред. 1997. Вып. 112. С. 139-147.

[7] Донцов В.Е. // ПМТФ. 1998. Т. 39. № 5. С. 19-24.

[8] Kusaiynov K., Sakipova S.E. // Mat. 10th Int. Conf. Method. Aerophys. Research. 2000. Part II. P. 120-124.

[9] Жанабаев З.Ж. Структурная теория гидродинамической турбулентности. Алматы, 1997. С. 54.

[10] Жанабаев З.Ж. // Изв. СО АН СССР. Сер. техн. наук. 1998. Вып. 5. № 8. С. 83-88.

[11] Кусаиынов К., Сакипова С.E. // Устойчивость течений гомогенных и гетерогенных жидкостей. Мат. VIII Междунар. конф. Новосибирск, 2001. С. 99-101. 